\title{
Riprap Stability: Transverse and Longitudinal versus Continuous Protections
}

\author{
Gustavo Adolfo M. de Almeida ${ }^{1}$ and Juan P. Martín-Vide ${ }^{2}$
}

\begin{abstract}
An experimental study was conducted to determine the influence of length, width, and protrusion of noncontinuous riprap protections on shear failure conditions. The incipient motion of particles as a failure criterion and the reference transport method as the threshold of motion were used. In each test, riprap transport rates were measured at different time intervals using a sediment trap placed immediately downstream from the test reach so that time dependence could be well described. Results reveal that incipient motion conditions of transverse (cross-sectional) protections are strongly influenced by both the protrusion and length of bed protection, which indicates that stability significantly increases as protection length increases and decreases as protrusion increases. In the case of longitudinal protections, almost the same failure conditions were found as in the case of continuous protection. Furthermore, these conditions are unrelated to the width of the protection. A coefficient to correct design formulas obtained by other authors is proposed to take into account the effect of the geometry of transverse protections on their stability.
\end{abstract}

DOI: 10.1061/(ASCE)HY.1943-7900.0000031

CE Database subject headings: Rivers; Erosion; Sediment transport; Riprap; Shear failure; Revetments.

\section{Introduction}

Rock riprap is widely used in river engineering to counteract bed and bank scouring. As a consequence, considerable effort has been devoted to developing new methodologies for determining its size, gradation, layer thickness, and filter characteristics. Most consider the general case of a continuous revetment (Stevens et al. 1976; Maynord et al. 1987; Escarameia and May 1995; Pilarczyk 1998) or very specific protections such as those used for bridge piers, but there seems to be an increasing trend to use riprap in other river engineering works. Among these applications, two types of noncontinuous bed protections are widely used: (1) transverse protections (cross sectional), such as bed sills (Fig. 1), or, similarly, protections for buried pipelines; and (2) longitudinal protections, such as bank protections with mild side slopes or any other buried longitudinal structure. It is common for these two types of protection to be partially buried, allowing for a certain degree of protrusion $p$ (Fig. 2). Pipelines are frequently buried in river channels or floodplains and they sometimes cross river channels. Protections against general scour, such as bed sills, (Martin-Vide and Andreatta 2006) are transverse and commonly based on riprap protections.

The flow field around these structures is extremely dependent on their particular geometry (length, width, and protrusion). Schiereck (2000) gives a complete description of flow character-

${ }^{1}$ Postdoctoral Researcher, Dept. of Hydraulic Engineering, Technical Univ. of Catalonia, C/Jordi Girona 1-3 Ed. D1, Barcelona, Spain (corresponding author). E-mail: gustavo.adolfo.mazza@upc.edu

${ }^{2}$ Professor, Dept. of Hydraulic Engineering, Technical Univ. of Catalonia, C/Jordi Girona 1-3 Ed. D1, Barcelona, Spain. E-mail: vide@ grahi.upc.edu

Note. This manuscript was submitted on May 25, 2007; approved on November 10, 2008; published online on February 6, 2009. Discussion period open until November 1, 2009; separate discussions must be submitted for individual papers. This paper is part of the Journal of Hydraulic Engineering, Vol. 135, No. 6, June 1, 2009. CASCE, ISSN 07339429/2009/6-447-456/\$25.00. istics around a smooth sill, where the increase in velocities over the sill is patent. The increase of velocities due to the contraction of the streamlines gives rise to a significant extra load. Another destabilizing mechanism arises due to the change of bed roughness. Some authors (Nezu and Tominaga 1994; Fredsoe et al. 1993) argue that a sudden change produces an overshooting property (an abrupt increase of the bed shear stress over the bed section with the larger roughness), while others (Chen and Chiew 2003) found a gradual increase. Whether or not overshooting is present, the increase in shear stress over the sill due to the change in bed roughness is clear. In addition to the increased shear stresses, the configuration of the particles in the protection reduces its stability. On the one hand, particles located in the first transverse line (upstream) will be more exposed to flow attack than particles embedded in the revetment. On the other hand, particles located in the last line will not count on the reaction force of a contiguous particle downstream. In the case of longitudinal riprap protections, the rougher area introduces a transverse distribution of shear stresses which must be taken into account. In this case, designing a protection to resist the mean cross-sectional shear stress may significantly underestimate the load. In summary, failure conditions of noncontinuous riprap protections may differ strongly from those observed in continuous protections.

This paper investigates the influence of geometrical variables such as length, width, and protrusion on shear failure in both transverse and longitudinal riprap protections by comparing their critical conditions with those observed in continuous riprap blankets. The analysis focuses on the shear failure mechanism or, in other words, the entrainment of the riprap by the flow. Other types of failure mechanisms (such as winnowing or erosion close to the protection edges) are not studied in this paper.

\section{Experimental Setup}

An experimental program was conducted in a 30-m-long, 0.75-m-wide, 0.60-m-deep glass-sided tilting flume. An area with 


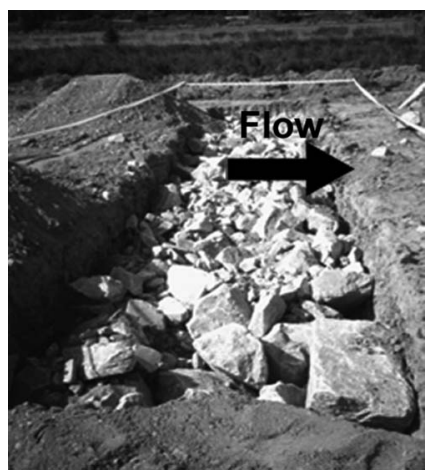

Fig. 1. Riprap bed sill under construction; Besòs River, close to Barcelona

dissipation screens was installed at the channel inlet to prevent large-scale disturbances. The test reach consisted of a 3-m-long recess located $9 \mathrm{~m}$ upstream from the channel outlet. Flow discharges were measured by a V-shaped, sharp-crested weir installed upstream of the channel. Velocity measurements were conducted using a three-dimensional (3D) acoustic Doppler velocimeter (ADV) manufactured by SonTek. The sampling frequency of the ADV was set to $25 \mathrm{~Hz}$ and the duration of the measurements at each point was $80 \mathrm{~s}$.

The slope of the flume could be set up to 0.04. An adjustable tailgate was used to control the tailwater in each experiment, making it possible to achieve uniform flow in the test reach. All the tests used the same flow depth of $Y=16.5 \mathrm{~cm}$. A point gauge with a precision of $0.1 \mathrm{~mm}$ was used for measuring water levels. Both the ADV and the point gauge were mounted on a motorized positioning system with an accuracy of $0.01 \mathrm{~mm}$ in the longitudinal and vertical directions.

Riprap particles displaced from the protection were weighed and counted after they had been collected in a $75 \mathrm{~cm}$ wide and $5 \mathrm{~cm}$ high sediment trap (Fig. 3), downstream of the test reach. The flow perturbation due to the removal and replacement of the trap during the experiments was considered negligible.

Riprap materials were represented by four types of uniformly distributed crushed rock particles that were fairly similar in shape. Particle characteristics are shown in Table 1 , where $W=$ mean particle weight; $D_{i}=$ gain size for which $i \%$ of the mixture is finer; $\lambda$ =porosity of the material; $N^{\prime}=$ number of surface particles per unit area; $\gamma_{s}$ and $\gamma_{w}=$ rock and water specific weight respectively;

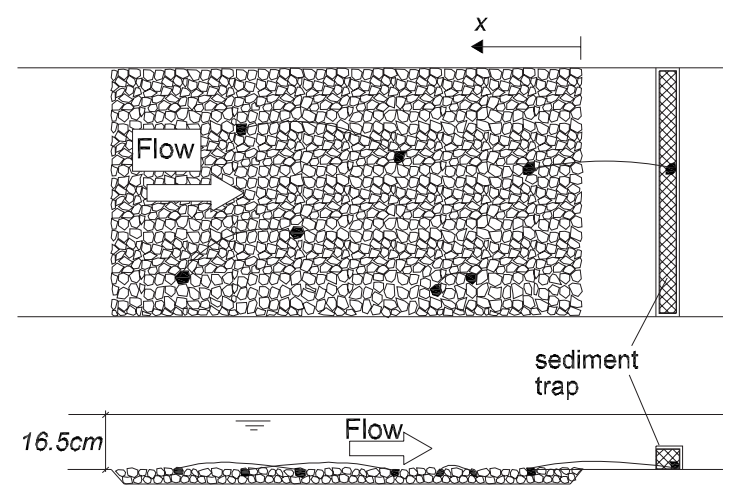

Fig. 3. Flume and sediment trap; note that number of trapped particles (one in sketch) is smaller than number of entrained particles (four)

$c / \sqrt{a b}=$ shape factor; $(a+b) / 2 c=$ flatness ratio; and $\sigma_{g}=$ gain size geometric standard deviation $\sigma_{g}=\sqrt{D_{84} / D_{16}}$.

Experiments were divided into three categories: continuous (C), transverse (T), and longitudinal (L) (Fig. 2). For the continuous bed experiments, the entire bottom of the $300-\mathrm{cm}$-long recess was filled with a layer of riprap particles the thickness of which is equal to $T=2 D_{50}$. To avoid problems related to internal boundary layer development, the first $100 \mathrm{~cm}$ of bed was filled with the same kind of particle and was then made rigid by gluing the rocks together. The remaining $200 \mathrm{~cm}$ of the movable bed was considered long enough to behave in the same way as continuous protection. Riprap particles were dropped into the recess and then leveled using a bar. Great care was taken while leveling in order to preserve the characteristics of "dumped" riprap.

Noncontinuous tests were prepared by dumping riprap particles inside a slot at the bottom recess. In T experiments, the slot had the same width as the flume, a depth (below the flume bottom) equal to $T=2 D_{50}$ and a variable length $l$. In L experiments, the slot was $260 \mathrm{~cm}$ long and had a variable width $b$. This slot was divided into three parts. From upstream to downstream, this division was as follows: a 78-cm-long reach with glued particles, a $162-\mathrm{cm}$-long reach with movable particles, and a $20-\mathrm{cm}-$ long reach with glued particles. The three reaches were built with the same protrusion. The rest of the bottom of the 3-m-long recess was a rigid bed made of mortar.

In both $\mathrm{T}$ and $\mathrm{L}$ experiments, the total weight of riprap to be dropped into the slot was previously estimated in order to obtain

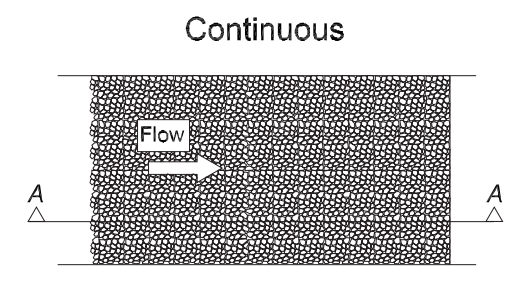

$A-A$

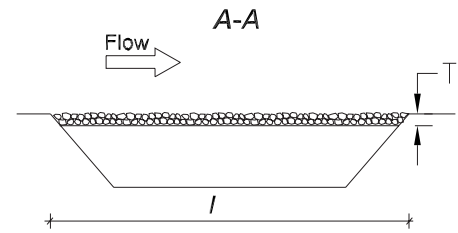

Transverse

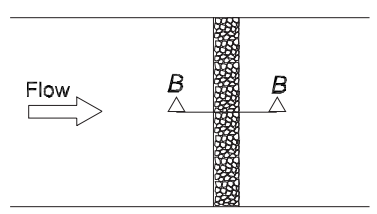

$B-B$

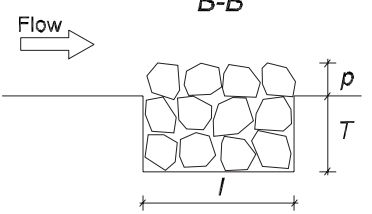

Longitudinal
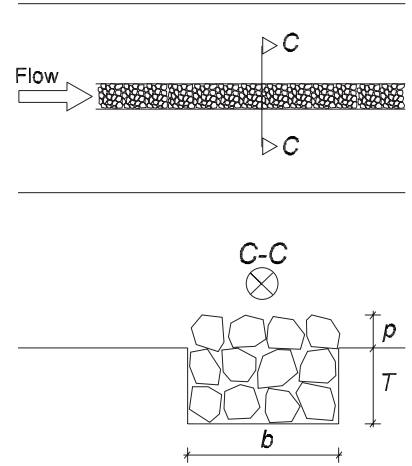

Fig. 2. Types of riprap protections tested: $l=$ length; $p=$ protrusion; $T=$ thickness; and $b=$ width 
Table 1. Riprap Particle Characteristics

\begin{tabular}{|c|c|c|c|c|c|c|c|c|c|c|c|}
\hline $\begin{array}{l}\text { Particle } \\
\text { type }\end{array}$ & $\begin{array}{c}D_{16} \\
(\mathrm{~cm})\end{array}$ & $\begin{array}{c}D_{30} \\
(\mathrm{~cm})\end{array}$ & $\begin{array}{c}D_{50} \\
(\mathrm{~cm})\end{array}$ & $\begin{array}{c}D_{84} \\
(\mathrm{~cm})\end{array}$ & $\sigma$ & $\frac{\gamma_{s}-\gamma_{w}}{\gamma_{w}}$ & $\begin{array}{c}W \\
N \times 10^{-2}\end{array}$ & $\lambda$ & $\begin{array}{c}N^{\prime} \\
\left(\text { part. } / \mathrm{m}^{2}\right)\end{array}$ & $c / \sqrt{a b}$ & $(a+b) / 2 c$ \\
\hline I & 0.66 & 0.74 & 0.85 & 1.10 & 1.29 & 1.89 & 0.50 & 0.33 & 8,252 & 0.54 & 2.03 \\
\hline II & 1.10 & 1.15 & 1.25 & 1.48 & 1.16 & 1.82 & 1.93 & 0.33 & 3,812 & 0.51 & 2.16 \\
\hline III & 1.33 & 1.42 & 1.57 & 1.80 & 1.16 & 1.92 & 3.40 & 0.32 & 2,534 & 0.55 & 2.01 \\
\hline IV & 1.60 & 1.68 & 1.75 & 1.93 & 1.10 & 1.92 & 5.16 & 0.32 & 2,039 & 0.56 & 2.01 \\
\hline
\end{tabular}

a certain value of protrusion $p$. The level of the topmost particles and the bottom level were then measured at several points using a point gauge, so that a more precise value of protrusion could be computed based on the difference between their mean values.

\section{Experimental Program}

The experimental program consisted of 17 series of tests (Table 2). Each series was characterized by a unique protection geometry and comprised several tests (at least eight). Each test was run with a different discharge within the range shown in Table 2.

To avoid errors related to the comparison of failure conditions of noncontinuous protections with the "universal" values found in the bibliography, $\mathrm{C}$ experiments were conducted to establish failure conditions in a continuous riprap blanket with the same characteristics (flume, rock characteristics, relative depth, etc.), and the criteria used in noncontinuous riprap experiments ( $\mathrm{T}$ and $\mathrm{L}$ ). In $\mathrm{C}$ experiments, velocity profiles were measured $1 \mathrm{~m}$ downstream from the upstream boundary of the test reach (slightly upstream from the interface between the glued and movable particles), at the center of the channel cross section.

$\mathrm{T}$ experiments aimed at verifying the influence of the protection length and protrusion on incipient motion conditions. In Series $5-8$, the four particle types were tested with a fixed value of relative length $l / D_{50}=4$ and an initial value of relative protrusion $p_{o} / D_{50}=0.95$. Series 6 and Series 9-12 all had the same characteristics $\left(b, D_{50}, p_{o}, Y\right)$ but had protections of varying lengths $l$.
Series 6,13 , and 14 used the same variables $\left(b, D_{50}, l, Y\right)$ but three different initial values of protrusion. In these $\mathrm{T}$ experiments, velocity profiles were measured $4 \mathrm{~cm}$ upstream from the transverse protection in order to provide a description of the undisturbed approach flow conditions instead of "local" ones (above the riprap protection).

The purpose of $\mathrm{L}$ experiments was to investigate the influence of the protection width $b$ on its failure conditions. As shown in Table 2, protections tested in Series 15-17 had the same characteristics and only differed in their width $\left(4,8\right.$, and $12 D_{50}$, respectively). Velocity profiles were measured slightly upstream from the interface between the movable particles and the upstream fixed particles, above the riprap protection.

The first step prior to each test was to adjust both the flume slope and the tailgate position to yield the water depth $Y$ $=16.5 \mathrm{~cm}$ for a given water discharge. After the bed had been prepared, the channel was slowly filled with water. The tailgate was slightly raised to increase the water level and ensure no bed motion. After steady flow conditions had been reached, the tailgate was lowered, a water depth of $16.5 \mathrm{~cm}$ was achieved and time began to be computed. During the tests, the water depth was measured using a point gauge in ten different positions in the test reach, at the center of the channel cross section. This experimental procedure was repeated for different water discharges in the ranges shown in Table 2 . This was achieved by changing the flume slope to obtain the same flow depth $(Y=16.5 \mathrm{~cm})$.

Transport rates of riprap particles were measured by removing the sediment trap and extracting the trapped solid material. The

Table 2. Experimental Program

\begin{tabular}{|c|c|c|c|c|c|c|c|c|c|c|c|}
\hline Series & Type & $\begin{array}{l}\text { Number of } \\
\text { tests }\end{array}$ & $\begin{array}{c}b \\
(\mathrm{~cm})\end{array}$ & $\begin{array}{c}l \\
(\mathrm{~cm})\end{array}$ & $\begin{array}{l}D_{50} \\
(\mathrm{~cm})\end{array}$ & $\begin{array}{l}p_{o} \\
(\mathrm{~cm})\end{array}$ & $\begin{array}{c}Q \text { range } \\
\left(1 \mathrm{~s}^{-1}\right)\end{array}$ & $\frac{l}{D_{50}}$ & $\frac{b}{D_{50}}$ & $\frac{p_{o}}{D_{50}}$ & $F$ range \\
\hline 1 & $\mathrm{C}$ & 14 & 75 & 200 & 0.85 & 0 & $90-120$ & 235 & 88 & 0 & $0.57-0.76$ \\
\hline 2 & $\mathrm{C}$ & 41 & 75 & 200 & 1.25 & 0 & $90-132.5$ & 160 & 60 & 0 & $0.57-0.84$ \\
\hline 3 & $\mathrm{C}$ & 8 & 75 & 200 & 1.57 & 0 & $95-135$ & 127 & 48 & 0 & $0.60-0.86$ \\
\hline 4 & $\mathrm{C}$ & 8 & 75 & 200 & 1.75 & 0 & $124-155$ & 114 & 43 & 0 & $0.79-0.98$ \\
\hline 5 & $\mathrm{~T}$ & 8 & 75 & 3.4 & 0.85 & 0.81 & 60-95 & 4 & 88 & 0.95 & $0.38-0.60$ \\
\hline 6 & $\mathrm{~T}$ & 45 & 75 & 5.0 & 1.25 & 1.19 & $80-132.5$ & 4 & 60 & 0.95 & $0.51-0.84$ \\
\hline 7 & $\mathrm{~T}$ & 8 & 75 & 6.3 & 1.57 & 1.49 & $95-130$ & 4 & 48 & 0.95 & $0.60-0.83$ \\
\hline 8 & $\mathrm{~T}$ & 8 & 75 & 7.0 & 1.75 & 1.66 & $95-130$ & 4 & 43 & 0.95 & $0.60-0.83$ \\
\hline 9 & $\mathrm{~T}$ & 8 & 75 & 10 & 1.25 & 1.19 & $95-130$ & 8 & 60 & 0.95 & $0.60-0.83$ \\
\hline 10 & $\mathrm{~T}$ & 8 & 75 & 20 & 1.25 & 1.19 & $95-130$ & 16 & 60 & 0.95 & $0.60-0.83$ \\
\hline 11 & $\mathrm{~T}$ & 8 & 75 & 35 & 1.25 & 1.19 & $95-130$ & 28 & 60 & 0.95 & $0.60-0.83$ \\
\hline 12 & $\mathrm{~T}$ & 8 & 75 & 50 & 1.25 & 1.19 & $95-130$ & 40 & 60 & 0.95 & $0.60-0.83$ \\
\hline 13 & $\mathrm{~T}$ & 8 & 75 & 5 & 1.25 & 0.35 & $95-130$ & 4 & 60 & 0.28 & $0.60-0.83$ \\
\hline 14 & $\mathrm{~T}$ & 21 & 75 & 5 & 1.25 & 0.76 & $80-130$ & 4 & 60 & 0.61 & $0.51-0.83$ \\
\hline 15 & $\mathrm{~L}$ & 8 & 5 & 162 & 1.25 & 1.63 & $95-130$ & 130 & 4 & 1.30 & $0.60-0.83$ \\
\hline 16 & $\mathrm{~L}$ & 8 & 10 & 162 & 1.25 & 1.63 & $95-130$ & 130 & 8 & 1.30 & $0.60-0.83$ \\
\hline 17 & $\mathrm{~L}$ & 8 & 15 & 162 & 1.25 & 1.63 & $95-130$ & 130 & 12 & 1.30 & $0.60-0.83$ \\
\hline
\end{tabular}

Note: $\mathrm{C}=$ continuous; $\mathrm{T}=$ transverse; $\mathrm{L}=$ longitudinal. $l$ and $b$ are illustrated in Fig. $2, p_{o}$ is the initial value of $p$ and $\mathrm{F}=$ Froude number. 
time dependence of transport rates may result in major errors in incipient motion determination and must be taken into account. Measurements of transport rates were made at different time intervals. The first measurement was taken at $t=40 \mathrm{~s}$ and time intervals gradually increased until $\Delta t=5 \mathrm{~min}$ at $t=10 \mathrm{~min}$. After $t$ $=10 \mathrm{~min}$, all measurements were taken at $\Delta t=5 \mathrm{~min}$ intervals. Almost all the experiments lasted for a total of $1 \mathrm{~h}$. More details on the experiments are given in Almeida (2007).

\section{Basis for Analysis}

\section{Reference Transport Method}

In this research, the incipient motion of particles was used as a failure criterion. Some authors (Buffington and Montgomery 1997) have highlighted a considerable scatter in critical dimensionless shear stress $\left(\tau_{c}^{*}\right)$ values. This scatter could be explained by differences in the experimental conditions and methodologies used by each author. The reference transport method is used in this paper to estimate critical shear stresses for the initiation of motion. The method consists of applying different shear stresses to a bed and measuring the corresponding bed-load transport rates. Subsequently, after the relation between shear stress and transport rates has been fitted, the threshold value of bed shear stress may be determined by extrapolating the transport rate to zero or to an arbitrary definition of a small but finite constant transport rate (Wilcock 1998; Parker et al. 1982; Fenton and Abbott 1977; Shvidchenko and Pender 2000). Several reference transport parameters have been proposed to represent the level of transport activity, most of which represent bed mobility as a dimensionless form of unit transport rates (Parker et al. 1982; Einstein 1950).

Shvidchenko and Pender (2000) have linked incipient motion to the probability of sediment entrainment through the intensity of sediment motion

$$
I=\frac{m}{N \Delta t}
$$

in which $I=$ intensity of sediment motion; and $m=$ number of entrained particles observed during time interval $\Delta t$ in an area that contains $N$ surface particles. As stated by Einstein (1942) [extracted from Shvidchenko and Pender (2000)], I can be regarded as the probability that a particle will be detached from the bed in a given unit time interval.

By defining the cumulative fractional number of entrainment $\Lambda$ as

$$
\Lambda=\frac{\sum_{t=0}^{t} m}{N}
$$

where $t=0$ refers to the beginning of the test, $I$ may at any instant now be regarded as the derivative of $\Lambda$ with respect to time

$$
I=\frac{d \Lambda}{d t}
$$

In this study, the intensity of sediment motion [Eqs. (1) or (3)] is used as a measurement of bed activity. This approach requires measurements of the number of entrainments per unit bed area instead of the cross-section solid discharge measured in the experiments using the sediment trap. The relationship between these two variables, entrainment and bed load, is derived in the Appendix.

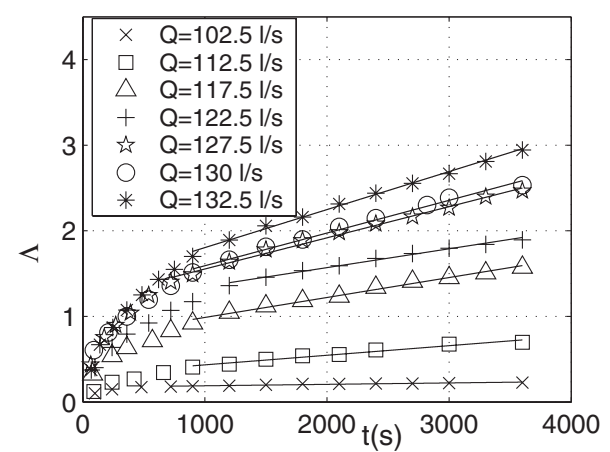

Fig. 4. Time evolution of $\Lambda$; Series 2 , continuous riprap revetment. Seven tests with discharges $Q$.

\section{Time Dependence}

As observed by other researchers (Shvidchenko and Pender 2000; Froehlich and Benson 1996), transport rates in experiments with a bed composed of dumped stones is not a constant but varies with time. The initial stages present a higher transport rate that asymptotically decreases to a steady value. Fig. 4 shows the time evolution in seven tests from Series 2 (continuous revetment). The values of $\Lambda$ were obtained by converting the number of particles collected in the sediment trap using the methodology presented in the Appendix. This is the typical behavior observed in continuous bed experiments and corresponds to the reorganization process of bed structures toward the more stable condition of a "water worked" bed. The steady values of $I$ reached after this reorganization will be used in this study to determine incipient motion. These values correspond to the slopes of the straight lines presented in Fig. 4, which were fitted for the time interval when the transport rates remained constant.

Transport rates in the case of transverse riprap protections also present higher values of $I$ in the first stages of the experiments, but they gradually drop to a zero transport rate. This phenomenon may be explained by the dependence of transport rates on protrusion, which varied significantly during the tests. Some authors have observed decreasing values of $\tau_{c}^{*}$ as particle protrusion increases (Fenton and Abbott 1977; James 1989; Coleman et al. 2003). During $T$ experiments, the erosion process reduced the protrusion of the protection, thus gradually increasing its stability. This behavior may be modeled by formulating a relationship between the protrusion

$$
p(t)=p_{0}-e(t)
$$

and the erosion rate, yielding

$$
\frac{d p}{d t}=-c_{1}\left(p-p_{e}\right)^{a}
$$

where $c_{1}$ and $a=$ constants; $p_{o}=$ initial protrusion (at $t=0$ ), $e(t)$ $=$ eroded thickness; and $p_{e}=$ equilibrium protrusion, defined as the value of $p$ for $t \rightarrow \infty$.

By integrating Eq. (5) and rearranging the constants, an expression for $p(t)$ may be written as

$$
p=c_{2}\left(a t-t+c_{3}\right)^{1 /(1-a)}+p_{e}
$$

where $c_{2}$ and $c_{3}=$ constants obtained by rearranging the other constants.

By substituting Eq. (4) for Eq. (6) and expressing the eroded thickness $e(t)$ as a function of the number of trapped particles, the cumulative fractional number of entrainments may be written as 


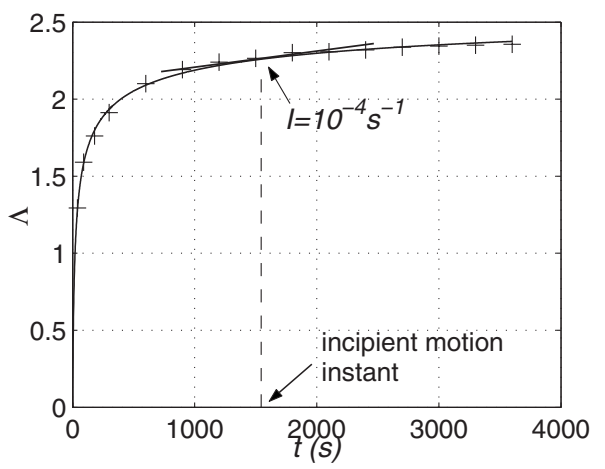

Fig. 5. Determination of incipient motion instant; Series 5, transverse protection, $Q=95 \mathrm{~L} \mathrm{~s}^{-1}$

$$
\Lambda=\frac{1}{\Gamma N^{\prime} \psi}\left[-c_{2}\left(a t-t+c_{3}\right)^{1 /(1-a)}+p_{0}-p_{e}\right]
$$

where $N^{\prime}=$ number of surface particles per unit area (see Table 1); $\psi=$ conversion factor between bed load and entrainments (defined in the Appendix); and $\Gamma=$ eroded thickness per unit trapped particle

$$
\Gamma=\frac{W}{\gamma_{s}(1-\lambda) A}
$$

where $A=$ protection area; and $\gamma_{s}, W$, and $\lambda=$ particle characteristics presented in Table 1.

The four constants $c_{2}, c_{3}, a$, and $p_{e}$ were obtained for each $\mathrm{T}$ experiment (Series 5-14) by the best-fitting Eq. (7). Fig. 5 shows an example of fitting Eq. (7) with the experimental data from one of the tests in Series 5.

L experiments were designed to simulate the situation in which the protection length was sufficiently large so that phenomena taking place close to its upstream and downstream boundaries could be considered negligible. This is why the particles were "inserted" between two reaches made up of glued particles that had the same protrusion. This longitudinal continuity eliminates the acceleration caused by protrusion observed in T tests. As a result, no dependence between transport rates and protrusion was observed in L experiments and time evolution followed the same pattern previously described for a continuous blanket.

\section{Incipient Motion Estimation}

Following the criterion used by Shvidchenko and Pender (2000), critical shear stresses were determined as the bed shear stresses that yielded an intensity of sediment motion $I=10^{-4} \mathrm{~s}^{-1}$.

In both $\mathrm{C}$ and $\mathrm{L}$ experiments, $I$ values were taken as those corresponding to the "water worked" situation by fitting the straight lines of $\Lambda$ as a function of $t$ once a constant transport rate was reached. Fig. 4 shows the time evolution of $\Lambda$ and the fitted lines for Series 2 experiments.

Furthermore, bed shear stresses were calculated by

$$
\tau_{o}=\rho v_{*}^{2}
$$

where $v_{*}=$ shear velocity estimated for each test by fitting the logarithmic velocity profile

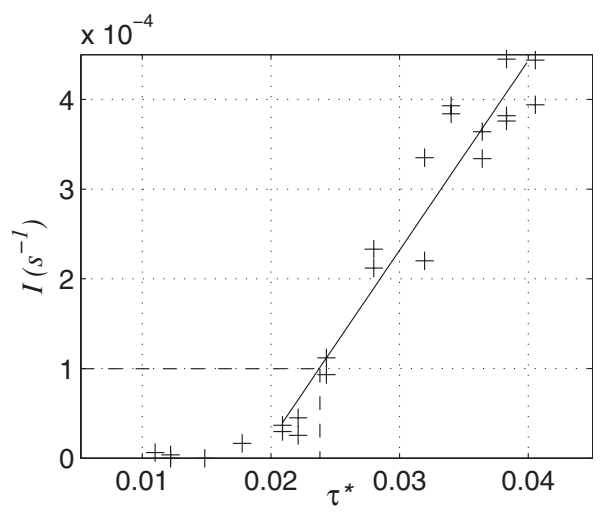

Fig. 6. Estimation of critical shear stress; Series 2: continuous revetment

$$
\frac{V}{v_{*}}=\frac{1}{K} \ln \left(\frac{y}{y_{o}}\right)
$$

where $V=$ streamwise velocity and $K$ is the von Kármán constant.

A sensitivity analysis on shear velocities results was carried out to determine the influence of (1) the datum level; (2) the deviations from logarithmic profiles in the outer flow region; and (3) the choice of using fitted or fixed values for $y_{o}$. The results showed that the best correlations were achieved when using data including part of outer flow layer and fitting both $v_{*}$ and $y_{o}$.

$I$ values were then plotted against dimensionless bed shear stresses $\tau^{*}$

$$
\tau^{*}=\frac{\tau_{o}}{\left(\gamma_{s}-\gamma_{w}\right) D_{50}}
$$

and a linear relation was fitted. Fig. 6 shows the relationship between $\tau^{*}$ and $I$ obtained for Series 2 .

In $\mathrm{T}$ experiments, velocity profiles were measured $8 \mathrm{~cm}$ upstream from the protection edge where velocities could be assumed to be undisturbed by the riprap. As a result, $\tau_{o}$ values may be considered representative of the bed stress of the approach flow rather than the shear stress above the riprap protection. Although the latter stress is the most suitable to describe particle dislodgement within the protection, the former seems to be the most suitable for engineering applications. In $\mathrm{C}$ and $\mathrm{L}$ experiments velocity profiles were measured in the last (downstream) cross section of the glued bed. In all cases velocity profile development was checked by velocity measurements along the $x$ coordinate.

In transverse protections, with a given value of $\tau_{o}$, the intensity of sediment motion gradually decreases with time as the protection is being eroded. As a result, each value of $I(t)$ may be associated with a specific value of protection protrusion $p(t)$. The time derivative of Eq. (7) gives the function $I(t)$ and the time instant corresponding to incipient motion may be found by

$$
\frac{d \Lambda}{d t}=I(t)=10^{-4}
$$

Fig. 5 illustrates the instant corresponding to $I=10^{-4} \mathrm{~s}^{-1}$. The protrusion corresponding to the incipient motion $\left(p_{c}\right)$ is finally calculated using Eq. (6). 


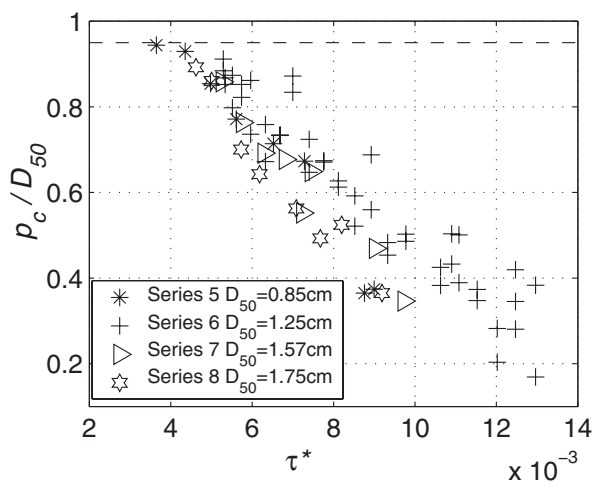

Fig. 7. Critical protrusion for Series 5, 6, 7, and 8; dashed line corresponds to $p_{o}$

\section{Results}

\section{Transverse Protections}

Fig. 7 plots the relationship between the critical protrusion $p_{c}$, made dimensionless with $D_{50}$, and $\tau^{*}$ for Series 5-8. These series have the same values of $l / D_{50}=4$ and $p_{o} / D_{50}=0.95$ but each of them corresponds to one of the four rock types presented in Table 1. It might be argued whether water depth should be used instead of $D_{50}$ for scaling $p_{c}$. However, during the experiments there were no significant changes in the water surface elevation between the upstream reach and the protection cross section (see Fig. 8). Furthermore, in most of the experiments $p_{c}$ was less than $7 \%$ of the flow depth. The best data collapse was obtained using $D_{50}$ for scaling $p_{c}$.

The results show that the dimensionless shear stress for the "complete stability" of a transverse protection $\left(p_{c}=p_{o}=0.95 D_{50}\right)$ is one order of magnitude lower than Shields' critical stress values for a continuous blanket found in the literature. For increasing $\tau^{*}$ values, there is a linear reduction of critical protrusion values. Extrapolating these results to $p_{c} \simeq 0$, a dimensionless shear stress $\tau^{*} \simeq 0.016$ is obtained. In other words, the bed sill is "swept" to the general bed level when $\tau^{*} \simeq 0.016$.

The influence of relative length $l / D_{50}$ on incipient motion conditions is shown in Fig. 9, where results are shown for various series with different $l / D_{50}$ but the same values for both $p_{o}$ and $D_{50}$. Values of $p_{c} / D_{50}$ are plotted against shear stress, which are made dimensionless using the critical shear stress found for continuous protection tests $\left(\tau_{\mathrm{cc}}\right)$. Fitted linear relationships corre-

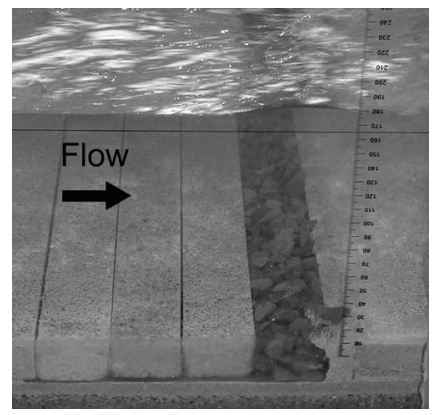

Fig. 8. Transverse riprap test; shortest bed under test conditions

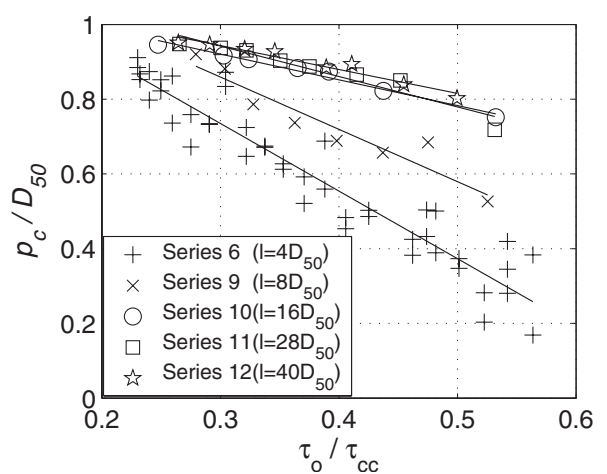

Fig. 9. Analysis of influence of relative length on critical protrusion values; transverse protections compared with continuous protections

sponding to each series are also plotted. Data from Series 6 are used both in Fig. 7 for the effect of protrusion and in Fig. 9 for the effect of length.

In Fig. 9, as $l / D_{50}$ increases stability is significantly enhanced. For a fixed value of critical relative protrusion, say $p_{c} / D_{50}=0.8$, shear stress for a relative length $l / D_{50}=16$ is almost twice the corresponding value for $l / D_{50}=4$. For $l / D_{50} \geqslant 16$, this variable seems to have no influence on incipient motion conditions. Our final observation confirms the intuitive idea that as the protection becomes longer it tends to behave as continuous protection. $\tau_{o} / \tau_{\mathrm{cc}}$ does not approach unity for large values of $l$ because $\tau_{o}$ represents the approach flow conditions instead of the conditions at the top of the riprap protection.

Fitted lines for Series 10, 11, and 12 all have approximately the same slope, which is milder than that corresponding to Series 6 and 9 , indicating that the $p_{c}$ of a larger protection is less sensitive to shear stresses. Another feature in Fig. 9 is that all the fitted lines intersect $p_{c}=p_{o}=0.95 D_{50}$ for $\tau / \tau_{\mathrm{cc}}$ at around 0.2 (i.e., $20 \%$ of critical shear stress for a continuous revetment).

The influence of initial protrusion is analyzed in Fig. 10, which presents three series of experiments with different values of initial protrusion $p_{o}$ but with the same values of $l$ and $D_{50}$. Designing protections with protrusion values corresponding to the "stable area" in Fig. 9 (below the straight lines) does not ensure that no motion will occur. Even for very low initial protrusions, some displacements were recorded. In other words, the equilibrium height of a higher bed sill attained after $1 \mathrm{~h}$ of flow does not imply that a bed sill of this initial height (achieved by dumping

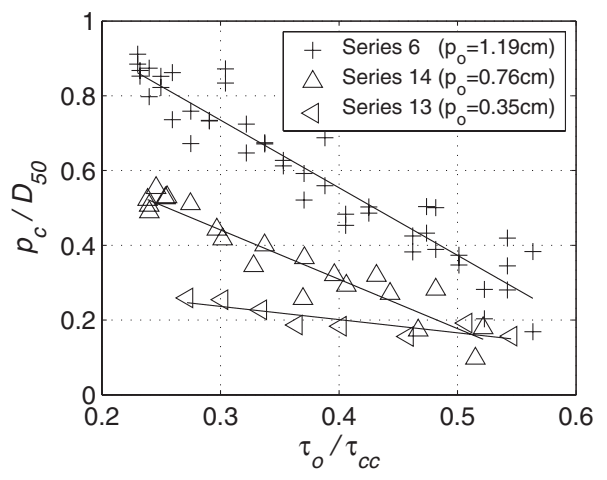

Fig. 10. Analysis of influence of initial values of relative protrusion on incipient motion conditions; transverse protections 


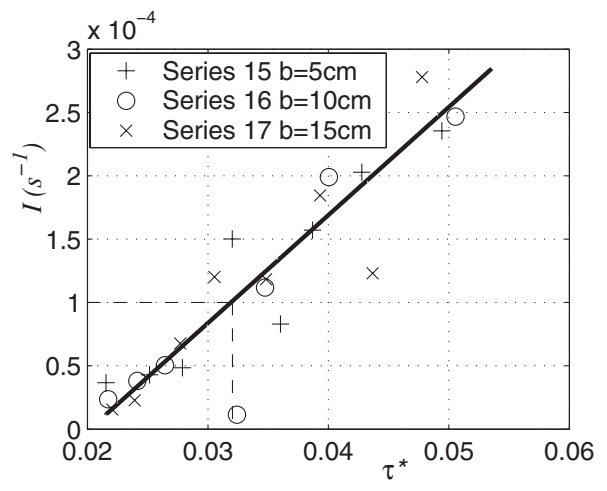

Fig. 11. Relationship between shear stress and intensity of sediment motion in $L$ experiments. Value of $\tau^{*}$, corresponding to $I=10^{-4} \mathrm{~s}^{-1}$, is taken as critical dimensionless shear stress.

riprap) is stable under the same flow. For practical purposes, the idea of a sacrifice thickness to take this into account is recommended.

\section{Longitudinal Protections}

Fig. 11 shows the relationship between $\tau^{*}$ and $I$ for L experiments. Results from Series 15, 16, and 17 almost overlap so that no relationship was found between the width of the protection and its failure conditions. The line presented in Fig. 11 was obtained by fitting data from Series 15, 16, and 17 together. Using $I$ $=10^{-4} \mathrm{~s}^{-1}$ as the criterion for incipient motion conditions, $\tau^{*}$ may be estimated as 0.032 . This value is quite similar to incipient motion shear stress found for a continuous blanket with the same particle type $\left(\tau_{c}^{*}=0.025\right.$, in Series 2 -Fig. 6). It must be highlighted that shear stresses used in the case of longitudinal protections were obtained by fitting the logarithmic law to the velocity profiles measured above the riprap protection. These profiles were obviously influenced by riprap roughness and may therefore be considered "local" rather than mean cross-section stresses. This observation is crucial for design purposes, since cross-sectional shear stress distribution must be evaluated first in order to perform any riprap sizing.

\section{Practical Applications}

The remarkable difference between incipient motion conditions of continuous and transverse protections draws attention to the need for improvements of riprap sizing methodologies, so that the discontinuity effect is taken into account. A discontinuity factor $\Omega$ is proposed to increase riprap size as a function of the protection geometry. $\Omega$ values were obtained by comparing experimental results with the design formula proposed by Maynord et al. (1987)

$$
\frac{D_{30 M}}{Y}=0.30\left[\left(\frac{\gamma_{w}}{\gamma_{s}-\gamma_{w}}\right)^{0.5} \frac{V}{\sqrt{g Y}}\right]^{2.5}
$$

where $D_{30 M}=$ grain size $D_{30}$ by Maynord et al. (1987). The discontinuity factor is now defined as

$$
\Omega=\frac{D_{30 e}}{D_{30 M}}
$$

where $D_{30 e}=$ grain size $D_{30}$ used in each experiment.

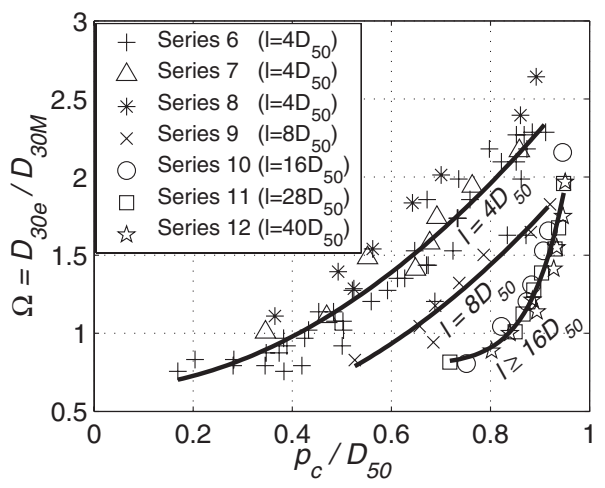

Fig. 12. Discontinuity factor as function of geometrical characteristics of riprap protection

Fig. 12 shows the relationship obtained between $\Omega$ and the geometrical parameters that influence protection failure. Based on this figure, the values of $\Omega$ in Table 3 are suggested for first estimation of riprap size. It should be stressed, however, that these results were obtained from a limited data set, and more research is necessary to extend the range of applicability to other situations. One important limitation of the experiments is the ratio of riprap roughness/bed roughness, which ranges from 21 to 43 . These results are within the same order of magnitude of the stability factor found by Pilarczyk (1998) for the effect of edges (about 1.5-2.0 for the riprap size), and Izbash (1935) coefficients for isolated and embedded particles (about two times higher).

\section{Conclusions}

An experimental investigation of the effect of geometry parameters on shear failure of transverse and longitudinal riprap protections was performed.

In the case of a transverse protection, it was demonstrated that riprap size may be significantly underestimated if a design formula developed for continuous blankets is used. Results have shown that the full stability (no particle motion) of transverse riprap protection requires shear stress values one order of magnitude lower than Shields' critical values, as found in the bibliography, for continuous blankets and for approximately $20 \%$ of the critical values determined in this paper for a continuous riprap bed with the same riprap size. These values are strongly influenced by both the protrusion and the length of the riprap protection (see Fig. 9). Increasing the length of the protection significantly increases its stability. However, for relative lengths greater than $l=16 D_{50}$, it appears that this parameter has no effect on incipient motion conditions. A methodology based on a discontinuity factor $\Omega$ is proposed for sizing transverse riprap pro-

Table 3. Proposed Values of Discontinuity Factor $\Omega$ for $p_{c} / D_{50}$, Ranging from 0.2 to 0.95 , and for $l / D_{50}$, Ranging from 4 to Greater than 16

\begin{tabular}{lccccc}
\hline & \multicolumn{5}{c}{$p_{c} / D_{50}$} \\
\cline { 2 - 6 }$l / D_{50}$ & 0.2 & 0.4 & 0.6 & 0.8 & 0.95 \\
\hline 4 & 1.0 & 1.0 & 1.4 & 2.0 & 2.5 \\
8 & 1.0 & 1.0 & 1.0 & 1.5 & 1.9 \\
$\geqslant 16$ & 1.0 & 1.0 & 1.0 & 1.0 & 1.9 \\
\hline
\end{tabular}




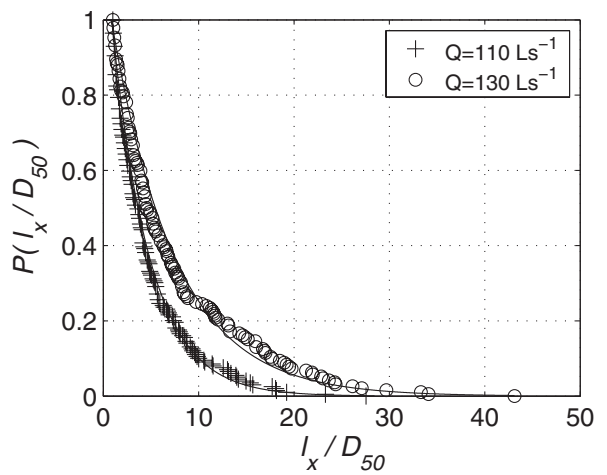

Fig. 13. Particle displacement distribution tests using rock Type II. Data observed (from video) in symbols and Eq. (15) in continuous line.

tections. Fig. 12 shows the behavior of $\Omega$ as a function of the protrusion and length parameters $\left(p_{c} / D_{50}\right.$ and $\left.l / D_{50}\right)$. These results are summarized in Table 3 .

Although all tests with transverse protections reached a stable protrusion for a given shear stress, designing the protection using this value does not ensure that no motion will occur. Particle entrainments were recorded even in experiments with initial protrusion values much lower than those corresponding to the "stable" protrusion reached in experiments with higher initial protrusion.

No remarkable differences were found between critical shear stress values of longitudinal and continuous riprap protections. Nevertheless, in this analysis shear values above the riprap protection were used, which may differ strongly from mean crosssectional ones. As a result, the successful sizing of longitudinal riprap protections must be based on the accurate estimation of cross-sectional shear stress distribution.

\section{Appendix. Conversion of Transport Rates into Intensity of Sediment Movement}

In this study, the relationship between cross-sectional solid transport and relative transport (i.e., the number of entrainments per unit bed area) is based on particle displacement statistics near incipient motion conditions.

Particle displacement distribution was estimated by using standard video-imaging techniques. Nine tests were conducted using rock Types II, III, and IV (Table 1) for flows ranging from $\tau^{*}$ $=0.022$ to 0.059 .

For each test, a number of displacements ranging from 100 to 200 was recorded. Displacements were recorded as transverse and longitudinal components $\left(l_{x}\right.$ and $\left.l_{y}\right)$. Only particle displacements of lengths greater than $1 D_{50}$ were considered. Data were fitted using an exponential cumulative probability distribution

$$
P\left(\frac{l_{p}}{D_{50}}\right)=e^{-\alpha\left[\left(l_{p} / D_{50}\right)-1\right]}
$$

where $P\left(l_{p} / D_{50}\right)=$ probability that dimensionless particle displacement $l_{p} / D_{50}$ is greater than a fixed value; and $l_{p}=$ absolute value of particle displacement in one of the two directions. Fig. 13 shows two examples of $l_{x}$ distribution and the corresponding fitted curves.
For longitudinal displacements, linear regression was then used to estimate a relationship between $\alpha$ and $\tau^{*}$, which resulted in

$$
P\left(\frac{l_{x}}{D_{50}}\right)=e^{\left(3.04 \tau^{*}-0.29\right)\left(l_{x} / D_{50}-1\right)}
$$

In the case of transverse displacements, no relationship was found between $\alpha$ and $\tau^{*}$ within the range of $\tau^{*}$ tested. Thus, $\alpha$ was determined by fitting data from all the experiments together, which yielded

$$
P\left(\frac{l_{y}}{D_{50}}\right)=e^{-0.97\left(y / D_{50}\right)}
$$

Using these distributions, we wish to derive the relationship between the fraction of displaced particles $m / N$ and the total number of particles collected by the sediment trap $N_{t}$. Two assumptions are made for this derivation. The first is that the particle will always reach the sediment trap after crossing one of the three boundaries (two lateral borders, and the transverse, downstream boundary). This assumption is reasonable, considering that there is less friction with the bed (in comparison with the riprap itself) and greater exposure to flow. Visual observations during the experiments also validate this assumption. The second is that the probability of particle entrainment is not dependent on its position.

The number of particles $n_{t}$ that are dislodged from the area element $d A$ and that eventually reach the sediment trap may be written as

$$
n_{t}=\left(m^{\prime} d A\right) P(\xi)
$$

where $m^{\prime}=$ number of particle displacements per unit area; and $P(\xi)=$ probability that the event "leaves the protection" (once displaced from its original position) occurs.

In the case of a transverse protection, the probability is that the particle longitudinal displacement $l_{x}$ is greater than its distance $x$ to the downstream boundary of the protection. Assuming that the probability of the particle leaving the protection once displaced is equal to one for all particles located at a distance smaller than $1 D_{50}$ from the boundary

$$
F(x)=P(\xi)=\left\{\begin{array}{ll}
1, & x<D_{50} \\
e^{\left(3.04 \tau^{*}-0.29\right)\left(x / D_{50}\right)}, & x \geqslant D_{50}
\end{array} \quad \forall y\right.
$$

By substituting Eq. (19) for Eq. (18) and integrating over the total length

$$
N_{t}=m^{\prime} B \int_{0}^{l} F(x) d x
$$

where $B=$ total channel width; $l=$ total length of movable particles; and $N_{t}=$ total number of particles collected by the sediment trap.

By defining $\psi$ as the ratio $N_{t} / m^{\prime}$ and $N^{\prime}$ as the total number of surface particles per unit area yields

$$
\begin{gathered}
\psi=B \int_{0}^{l} F(x) d x \\
\frac{m}{N}=\frac{N_{t}}{N^{\prime} \psi}
\end{gathered}
$$

Now, if $N_{t}=$ total number of trapped particles since $t=0$, from Eq. (2) 


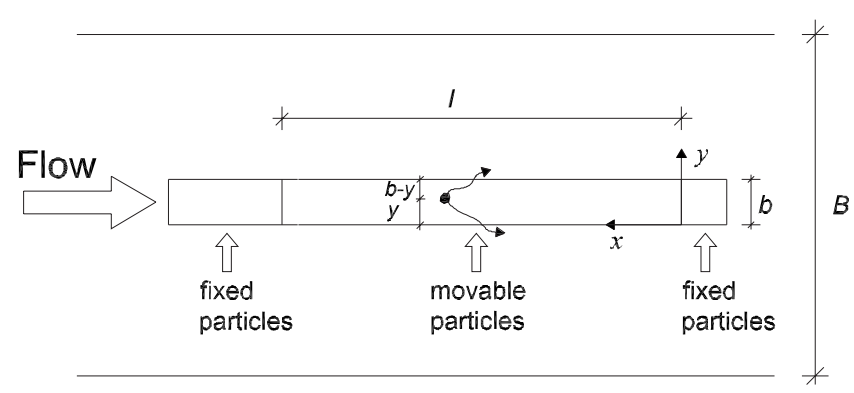

Fig. 14. Longitudinal protection

$$
\Lambda=\frac{N_{t}}{N^{\prime} \psi}
$$

Eqs. (21) and (23) allow us to convert the total number of particles collected by the sediment trap $N_{t}$ into the cumulative fractional number of entrainments $\Lambda$ for transverse protections.

In the case of longitudinal protections, in addition to longitudinal displacements we must take into account transverse movements. Therefore, the probability that particles displaced from their original positions will reach the sediment trap may be written as

$$
P(\xi)=\frac{1}{2} P[(x) \cup(y)]+\frac{1}{2} P[(x) \cup(b-y)]
$$

where $x$ and $y=$ particle coordinates, as shown in Fig. 14 .

In Eq. (24), $P(x), P(y)$, and $P(b-y)=$ respectively, probabilities that particle displacement $l_{x}$ be greater than its position $x$ and that displacement $l_{y}$ be greater than $y$ or greater than $(b-y)$. As a result

$$
\begin{aligned}
P(\xi)= & \frac{1}{2}[F(x)+G(y)-F(x) G(y)] \\
& +\frac{1}{2}[F(x)+G(b-y)-F(x) G(b-y)]
\end{aligned}
$$

where $G(y)$ is

$$
G(x)=\left\{\begin{array}{ll}
1, & y<D_{50} \\
e^{-0.97\left(y / D_{50}\right)}, & y \geqslant D_{50}
\end{array} \quad \forall x\right.
$$

Integrating Eq. (18) over the movable bed surface yields

$$
N_{t}=m^{\prime} \int_{0}^{l} \int_{0}^{b} P(\xi) d y d x
$$

By substituting Eq. (26) for Eq. (27) and operating

$$
\frac{N_{t}}{m^{\prime}}=\psi=b \int_{0}^{l} F(x) d x+l \int_{0}^{b} G(y) d y-\int_{0}^{l} F(x) \int_{0}^{b} G(y) d y d x
$$

The values of $N^{\prime}$ were determined for each particle type by counting the number of surface particles contained in an area of known dimensions. Eqs. (28) and (23) provide the solution for converting measured $N_{t}$ into $\Lambda$ in L experiments. As an example of the results of the conversion, in the case of Series 1-4 (C experiments), values of $m / N_{t}$, i.e., the ratio between entrained and trapped particles ranged from 11 to 43 . On the contrary, for Series 5-8 (T experiments with $l / D_{50}=4$, which are the shortest transverse protections) the same ratio ranged from 1.28 to 1.32 , only.

\section{Notation}

The following symbols are used in this paper:

$A=$ protection area;

$a, b, c=$ particle's minor, intermediate, and major axes;

$B=$ channel width;

$b=$ protection width;

$D_{i}=$ grain size for which $\mathrm{i} \%$ of grains are finer;

$D_{30 e}=D_{30}$ grain size used in each experiment;

$D_{30 M}=D_{30}$ grain size given by Maynord et al. (1987);

$e(t)=$ eroded thickness;

$\mathrm{F}=$ Froude number;

$g=$ gravitational acceleration;

$I=$ intensity of sediment motion;

$K=$ von Kármán constant;

$l=$ protection length;

$l_{x}=$ longitudinal particle displacement;

$l_{y}=$ transverse particle displacement;

$m=$ number of entrained particles;

$m^{\prime}=$ number of particle displacements per unit area;

$N=$ number of surface particles;

$N^{\prime}=$ number of surface particles per unit area;

$N_{t}=$ number of trapped particles;

$P(\xi)=$ probability that the event "particle leaves protection" (once it is displaced from its original position) will occur;

$p=$ protection protrusion;

$p_{c}=$ critical protrusion;

$p_{e}=$ equilibrium protrusion;

$p_{o}=$ initial protrusion;

$Q=$ flow discharge;

$T=$ thickness of the riprap protection;

$t=$ time;

$V=$ streamwise velocity;

$v_{*}=$ shear velocity;

$W=$ mean particle weight;

$Y=$ flow depth;

$\alpha=$ constant;

$\Gamma=$ eroded thickness per unit trapped particle;

$\gamma_{s}=$ particle specific weight;

$\gamma_{w}=$ water specific weight;

$\Delta t=$ time interval;

$\Lambda=$ cumulative fractional number of entrainments;

$\lambda=$ porosity;

$\rho=$ water density;

$\sigma_{g}=$ grain size standard deviation;

$\tau^{*}=$ dimensionless shear stress;

$\tau_{c}^{*}=$ critical dimensionless shear stress;

$\tau_{\mathrm{cc}}=$ critical shear stress of a continuous riprap blanket;

$\tau_{o}=$ undisturbed approach flow shear stress;

$\psi=$ conversion factor between bed load and entrainments; and

$\Omega=$ discontinuity factor.

\section{References}

Almeida, G. A. M. (2007). "Influence of geometry on the shear failure of a fluvial riprap protection. Experimental study." Ph.D. thesis, Technical Univ. of Catalonia, Barcelona, Spain. 
Buffington, J. M., and Montgomery, D. R. (1997). "A systematic analysis of eight decades of incipient motion studies, with special reference to gravel-bedded rivers." Water Resour. Res., 33, 1993-2029.

Chen, X., and Chiew, Y.-M. (2003). "Response of velocity and turbulence to sudden change of bed roughness in open-channel flow." J. Hydraul. Eng., 129, 35-43.

Coleman, S. E., Melville, B. W., and Gore, L. (2003) "Fluvial entrainment of protuding fractured rock." J. Hydraul. Eng., 129, 872-884.

Einstein, H. A. (1942). "Formulae for the transportation of bedload." Trans. Am. Soc. Civ. Eng., 107, Paper No. 2140, 561-573.

Einstein, H. A. (1950). "The bed-load function for sediment transport in open channel flows." Technical Rep., U.S. Dept. of Agriculture, Soil Conservation Service, Washington, D.C.

Escarameia, M., and May, R. W. P. (1995). "Stability of riprap and concrete blocks in highly turbulent flows." Proc. Inst. Civ. Eng., Waters. Maritime Energ., 112, 227-237.

Fenton, J. D., and Abbott, J. E. (1977). "Initial movement of grains on a stream bed: The effect of relative protrusion." Proc. Roy. Soc. Lond. A Math. Phys. Eng. Sci., 352, 523-537.

Fredsoe, J., Summer, B. M., Laursen, T. S., and Pedersen, C. (1993). "Experimental investigation of wave boundary layers with a sudden change in roughness." J. Fluid Mech., 252, 117-145.

Froehlich, D. C., and Benson, C. A. (1996). "Sizing dumped rock riprap." J. Hydraul. Eng., 122, 389-396.

Izbash, S. V. (1935). Construction of dams by dumping stones in flowing water, I z v. N I I G, Moscow-Leningrad.
James, C. S. (1989). "Prediction of entrainment conditions for nonuniform noncohesive sediments." J. Hydraul. Res., 28, 25-41.

Martín-Vide, J. P., and Andreatta, A. (2006). "Disturbance caused by bed sills on the slopes of steep streams." J. Hydraul. Eng., 132, 11861194.

Maynord, S. T., Ruff, J. F., and Abt, S. R. (1987). "Riprap design.” J. Hydraul. Eng., 115, 937-949.

Nezu, I., and Tominaga, A. (1994). "Response of velocity and turbulence to abrupt changes from smooth to rough beds in open-channel flow." Proc. Symp. of Fundamentals and Advances in Hydraulic Measurements and Experimentation, 195-204.

Parker, G., Klingeman, P. C., and McLean, D. G. (1982). "Bedload and size distribution in paved gravel-bed streams." J. Hydr. Div., 108, $544-571$.

Pilarczyk, K. W. (1998). Dikes and revetments: Design, maintenance and safety assessment, Balkema, Rotterdam, The Netherlands.

Schiereck, G. J. (2000). Introduction to bed, bank and shore protection, VSSD, Delft, The Netherlands.

Shvidchenko, A. B., and Pender, G. (2000). "Flume study of the effect of relative depth on the incipient motion of coarse uniform sediments." Water Resour. Res., 36, 619-628.

Stevens, M. A., Simons, D. B., and Lewis, G. L. (1976). "Safety factors for riprap protections." J. Hydr. Div., 102, 637-655.

Wilcock, P. R. (1988). "Methods for estimating the critical shear stress of individual fractions in mixed-size sediment." Water Resour. Res., 24, $1127-1135$ 